\title{
Post-COVID Neuropsychiatric Sequelae in India: Are We Ready for it?
}

\author{
Mahesh Gowda ${ }^{1}$, Guru S Gowda ${ }^{2}$
}

Indian Journal of Private Psychiatry (2021): 10.5005/jp-journals-10067-0086

Severe acute respiratory syndrome coronavirus 2-(SARS-CoV-2) is the pathogen responsible for coronavirus disease-2019 (COVID-19). ${ }^{1,2}$ As per World Health Organization (WHO), it has affected the 224 million population, and 4.62 million succumbed to death as of September 13, 2021, worldwide (in India-33 million population got affected and 0.44 million succumbed to death), resulted in global healthcare crises and strained health resources due to its pandemic. ${ }^{3}$

Among survivors, COVID-19 presented with constellation of persistent or emerging symptoms involving multiple organ systems like cardiovascular, pulmonary, renal, hematological, and neuropsychiatric beyond 4 weeks of infection. It demonstrates a similar, reinforcing concern following the SARS epidemic of 2003 and the Middle East respiratory syndrome (MERS) outbreak of 2012. ${ }^{1,4}$

Migraine-like headache, chronic malaise, diffuse myalgia, chronic fatigue, cognitive dysfunction ("brain fog"), depressive symptoms, and nonrestorative sleep are common neuropsychiatric post-COVID-19 sequelae. In addition, a few of them also have diagnosable depression, anxiety, and sleep disorders. Like other critical illnesses requiring intensive care, the complications of acute COVID-19 include stroke, hypoxic-anoxic damage, encephalopathy, altered sensorium, ataxia, amnesia, convulsion, and acute disseminated myelitis, which may lead to lingering or permanent neurological deficits requiring extensive neuropsychiatric rehabilitation. ${ }^{5,6}$ The prevalence varies between studies and ranges from 51 to $94 \%$. This variation in disorder prevalence may be due to sample size, the timing of post-COVID assessment, and the type of assessment and screening tool used. ${ }^{7}$ This burden adds to the community's existing COVID-19 related fear, panic, anxiety, sleep disorder, increased alcohol-related problems, and xenophobia in the general population. ${ }^{8}$ These are likely to have an adverse impact on the mental, physical, and cognitive health of COVID-19 survivors.

\section{What could be the Prevalence of Post- COVID-19 NEUROPSYCHIATRIC SYNDROME IN INDIA?}

India has had at least 33 million SARS-CoV-2 infections after ignoring the undetected infections, and $67.6 \%$ turned seropositive in the fourth round of National serosurvey conducted between June 14, 2021, and July 6, $2021^{9}$ Parliament of India (Ministry of Health and Family Welfare), Lok Sabha, Government of India. If we assume that $50 \%$ of SARS-CoV-2 infections result in post-COVID-19
${ }^{1}$ Director, Spandana Health Care Bengaluru, India

${ }^{2}$ Department of Psychiatry, National Institute of Mental Health and Neurosciences, Bengaluru, Karnataka, India

Corresponding Author: Mahesh Gowda, Director, Spandana Health Care Bengaluru, India, Phone: +919845134915, e-mail: maheshrgowda@ yahoo.com

How to cite this article: Gowda M, Gowda GS. Post-COVID Neuropsychiatric Sequelae in India: Are We Ready for It? Ind J Priv Psychiatry 2021;15(1):1-2.

Source of support: Nil

Conflict of interest: None

neuropsychiatric syndrome, India can expect 16.5 million people to suffer from post-COVID-19 neuropsychiatric syndrome.

\section{How to Bridge the Community's Neuropsychiatric Gap during the COVID Pandemic in India and What's Next?}

- Raising community awareness of the post-COVID-19 neuropsychiatric syndrome through information, education, and communication (IEC) activities.

- Scaling up and skill-building training of primary care doctors Doctor, Nurses, Community Health Workers and other allied healthcare and mental health professionals to screen and identify patients with anxiety, depression, sleep disturbances, post-traumatic stress disorder, dysautonomia, attention, dysexecutive symptoms, and fatigue among postCOVID-19 survivors to assess the post-COVID neuropsychiatric syndrome. .,6 $^{4}$

- Allowing telemedicine services to digitally screen for post-COVID neuropsychiatric syndrome and make an appropriate referral to a "post-COVID clinic."

- To begin interdisciplinary "post-COVID clinic" services in secondary and tertiary care centers in India for post-COVID syndrome.

- To develop evidence-based national clinical practice guidelines on post-COVID syndrome and enable the safe and effective practice.

- To fund research in this area in order to better understand the prevalence, a constellation of symptoms involving various organs, disability, burden, and policy-based clinical practice in India.

(o) The Author(s). 2021 Open Access This article is distributed under the terms of the Creative Commons Attribution 4.0 International License (https://creativecommons. org/licenses/by-nc/4.0/), which permits unrestricted use, distribution, and non-commercial reproduction in any medium, provided you give appropriate credit to the original author(s) and the source, provide a link to the Creative Commons license, and indicate if changes were made. The Creative Commons Public Domain Dedication waiver (http://creativecommons.org/publicdomain/zero/1.0/) applies to the data made available in this article, unless otherwise stated. 
- Appropriate policies should be developed to allocate independent funding and human resources to provide holistic evidence-based post-COVID syndrome treatment and research.

- The authority should monitor the policy implementation on "post-COVID syndrome care".

The ongoing COVID-19 pandemic-related mental health problems and post-COVID neuropsychiatric syndrome are major public health concerns both worldwide and in India. The technology-driven "post-COVID-19 clinic" can provide multidisciplinary, integrated, and holistic care to post-COVID survivors. There is a need for research, policy, a separate budget, and resource allocation to help reach the community's unreached vulnerable population.

\section{References}

1. Lu H, Stratton CW, Tang YW. Outbreak of pneumonia of unknown etiology in Wuhan, China: the mystery and the miracle. J Med Virol 2020;92(4):401-402. DOI: 10.1002/jmv.25678. PMID:31950516; PMCID: PMC7166628.

2. Gorbalenya AE, Baker SC, Baric RS, et al. Severe acute respiratory syndrome-related coronavirus: the species and its viruses-a statement of the coronavirus study group. bioRxiv 2020. DOI: 10.1101/2020.02.07.937862.
3. World Health Organisation (WHO). Available from: https://covid19. who.int/region/searo/country/in [Accessed on September 13 2021].

4. Nalbandian A, Sehgal K, Gupta A, et al. Post-acute COVID-19 syndrome. Nat Med 2021;27(4):601-615. DOI: 10.1038/s41591-021-01283-z.

5. Carfì A, Bernabei $R$, Landi $F$, et al. Persistent symptoms in patients after acute COVID-19. JAMA 2020;324(6):603-605. DOI: 10.1001/ jama.2020.12603.

6. Rogers JP, Chesney E, Oliver D, et al. Psychiatric and neuropsychiatric presentations associated with severe coronavirus infections: a systematic review and meta-analysis with comparison to the COVID-19 pandemic. Lancet Psychiatry 2020;7(7):611-627. DOI: 10.1016/S22150366(20)30203-0.

7. Carod-Artal FJ. Post-COVID-19 syndrome: epidemiology, diagnostic criteria and pathogenic mechanisms involved. Rev Neurol 2021;72(11):384-396. DOI: 10.33588/rn.7211.2021230.

8. Banerjee D, Vaishnav M, Rao TS, et al. Impact of the COVID-19 pandemic on psychosocial health and well-being in South-Asian (World Psychiatric Association zone 16) countries: a systematic and advocacy review from the Indian Psychiatric Society. Indian J Psychiatry 2020;62(Suppl. 3):S343-S353. DOI: 10.4103/psychiatry. IndianJPsychiatry_1002_20.

9. Parliament of India (Ministry of Health and Family Welfare), Lok Sabha, Government of India. Available from: http://loksabhaph nic.in/Questions/QResult15.aspx?qref=24949\&lsno=17 [Accessed on September 13, 2021]. 